\title{
Serum $\tau$ protein as a potential biomarker in the assessment of traumatic brain injury
}

\author{
JUNWEN WANG ${ }^{1}$, JUN LI $^{1}$, LIN HAN ${ }^{2}$, SONGBO GUO $^{2}$, LEI WANG $^{1}$, \\ ZUOJUN XIONG $^{1}$, ZHI CHEN ${ }^{1}$, WEN CHEN ${ }^{1}$ and JIAN LIANG ${ }^{1}$ \\ ${ }^{1}$ Department of Neurosurgery, Wuhan Central Hospital Affiliated to Tongji Medical College; \\ ${ }^{2}$ Department of Neurosurgery, Tongji Hospital Affiliated to Tongji Medical College, \\ Huazhong University of Science and Technology, Wuhan, Hubei 430014, P.R. China
}

Received November 10, 2014; Accepted December 22, 2015

DOI: $10.3892 / e t m .2016 .3017$

\begin{abstract}
Traumatic brain injury (TBI) is the leading cause of mortality and disabilities among all trauma cases. Following TBI, damage to axons results in $\tau$ protein hyperphosphorylation leading to microtubule instability and $\tau$-mediated neurodegeneration. In addition, $\tau$ protein is proteolytically cleaved and is able to access the cerebrospinal fluid (CSF) and serum; thus, this protein may serve as a potential biomarker in the diagnosis of injury severity and outcome prediction. Although a limited number of studies have investigated the CSF $\tau$ protein levels after TBI, the data are divergent and conflicting, and investigations into the serum $\tau$ protein levels have yet to be conducted. Therefore, the present study aimed to examine the serum $\tau$ protein levels in the full spectrum of TBI patients on days 0-14 after TBI, using an enzyme-linked immunosorbent assay. The protein levels were compared to the initial Glasgow Coma Score (GCS) and the Extended Glasgow Outcome Scale (GOS-E), which are used to represent the injury severity and patient outcome, respectively. In total, 56 patients, including 20 patients with mild TBI (GCS, 13-15), 19 patients with moderate TBI (GCS, 9-12) and 17 patients with severe TBI (GCS, 3-8), were included in the current study. The outcome was assessed 1 year after the injury and patients were classified into the good outcome (40 cases; GOS-E, 5-8) and poor outcome groups (16 cases; GOS-E, 1-4). The results indicated that serum $\tau$ protein levels increased soon after TBI and reached a peak value at $\sim 2$ days after the injury. The serum $\tau$ protein levels were significantly higher in the severe TBI group compared with those in the mild and moderate TBI groups $(\mathrm{P}<0.0001)$. Univariate analysis indicated that poor outcome was significantly associated with higher serum $\tau$ protein
\end{abstract}

Correspondence to: Dr Jun Li, Department of Neurosurgery, Wuhan Central Hospital Affiliated to Tongji Medical College, Huazhong University of Science and Technology, 26 Shengli Street, Wuhan, Hubei 430014, P.R. China

E-mail:wangcelia2013@gmail.com

Key words: $\tau$ protein, traumatic brain injury, biomarker, outcome levels on day $2(\mathrm{P}<0.0001)$. A receiver operating characteristic curve demonstrated that a $\tau$ protein level of $>116.04 \mathrm{pg} / \mathrm{ml}$ on day 2 resulted in a $93.75 \%$ sensitivity and $92.50 \%$ specificity for predicting a poor outcome. Furthermore, a $\tau$ protein level of $>372.1 \mathrm{pg} / \mathrm{ml}$ on day 2 yielded $100 \%$ sensitivity and $83.33 \%$ specificity for 1 year mortality in the severe TBI group. In conclusion, the present study suggests that serum $\tau$ protein may serve as a potential biomarker for evaluating the injury severity and predicting the outcome of TBI patients.

\section{Introduction}

Traumatic brain injury (TBI) is one of the leading causes of mortality and disability among all cases of trauma $(1,2)$. The incidence of TBI in China is $\sim 95 / 100,000$ people per year, which is similar to the incidence of stroke; however, TBI also affects younger individuals, resulting in a significant health care burden (3). A wide range of injuries are considered as TBIs, including mild, moderate and severe injuries (4). At present, the severity of TBI is typically evaluated by the Glasgow Coma Score (GCS) (4). The GCS characterizes the level of consciousness on the basis of motor, verbal and eye responses; the picture provided by these responses enables comparisons between patients and the assessment of changes in individual patients over time, and guides the management of these patients (4). The three components (motor, verbal and eye responses) can be scored separately or combined in a sum score, which ranges between 3 and 15 (4). Patients with TBI may be divided into three groups, according to their GCS scores: Severe TBI (GCS score, 3-8 points); moderate TBI (GCS score, 9-12 points); and mild TBI (GCS score, 13-15 points) (4). Certain clinical characteristics, such as the GCS score and the results of functional imaging studies, are well established for predicting the outcome of TBI patients (5). However, these are not accurate and are difficult to quantify in order to predict the outcome (5). No reliable predictors, particularly during the early stages following TBI, have been established to date. Therefore, it may be beneficial to establish a complementary approach using specific biochemical biomarkers in the assessment of TBI patients.

$\tau$ protein is a microtubule-associated protein with a molecular mass of 48-67 kDa (6). This protein binds to axonal 
microtubules and results in the formation of axonal microtubule bundles, which are essential structural elements in the axonal cytoskeleton (6). $\tau$ protein is abundant in the central nervous system (CNS), and in particular, in unmyelinated axons and cortical interneurons $(6,7)$. In addition, the $\tau$ protein can be detected in the cerebrospinal fluid (CSF) in the majority of cases, however, the determination of serum $\tau$ protein levels in healthy individuals is challenging (8). When damage to axons occurs following TBI, $\tau$ protein is released from the CNS into the CSF and serum, resulting in detectable levels of the serum protein (9). This suggests that serum $\tau$ protein may be a potential biomarker in the assessment of the outcome of TBI patients.

Several authors have investigated the CSF $\tau$ protein levels following TBI (10-12); however, the results of these studies are divergent and conflicting. To the best of our knowledge, research on serum $\tau$ protein in TBI patients has yet to be conducted. The predictive value of serum $\tau$ protein for TBI patients remains unclear. Therefore, the present study examined the serum $\tau$ protein levels at different time points subsequent to TBI, and compared the protein levels to the injury severity and 1-year outcomes of patients. The study attempted to determine whether serum $\tau$ protein levels reflect the injury severity and predict the outcome of TBI patients.

\section{Patients and methods}

Patient population. Ethical approval was obtained from the Wuhan Central Hospital (Wuhan, China), in accordance with the Helsinki Criteria. Written informed consent was obtained from all patients. A total of 56 patients ( 21 females and 35 males; age range, 18-54 years; mean age, 30.4 \pm 8.9 years) with closed TBI (brain tissue was not exposed), who were admitted to the Department of Neurosurgery at the Wuhan Central Hospital within $12 \mathrm{~h}$ after injury, were enrolled in the present study between June 2011 and July 2013. TBI had previously been diagnosed in these patients based on clinical characteristics, including: i) Complaint of patients; ii) symptoms, including a headache, vomiting and loss of consciousness; iii) a physical examination; and iv) imaging, including a computed tomography scan. Patients were divided into mild, moderate and severe TBI groups, according to their initial GCSs, which were determined immediately following admission. A total of 20 patients formed the mild TBI group (GCS, 13-15 points), 19 patients formed the moderate TBI group (GCS, 9-12 points) and 17 patients formed the severe TBI group (GCS, 3-8 points). All patients were managed according to the international guidelines for TBI management (13).

Exclusion criteria. The exclusion criteria were as follows: Age of $<18$ years or $>60$ years, admission to the hospital $>12 \mathrm{~h}$ after TBI, absence of informed consent, unavailability of blood sample, and absence of follow-up data. Patients with a history of neurological disabilities, severe cardiac disease, cervical spinal cord injury and other severe systemic diseases were also excluded from the present study.

$\tau$ protein analysis. Serum samples were obtained from the TBI patients at $12 \mathrm{~h}$ and at 1,2,3,4,7 and 14 days after TBI. Samples were collected in $10 \mathrm{ml}$ separator tubes and then

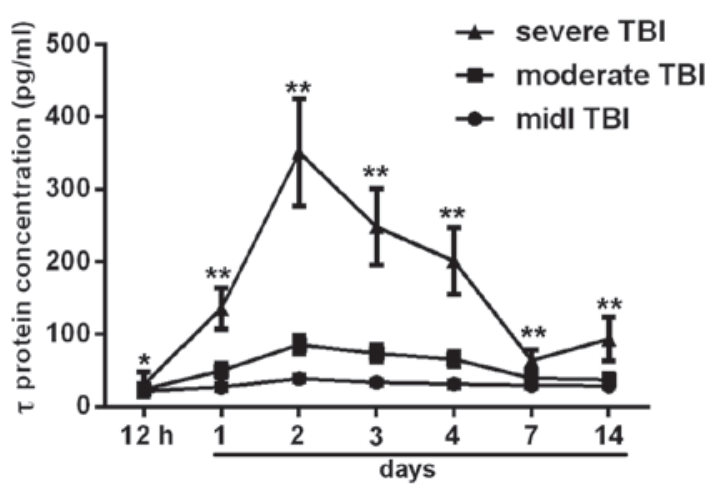

Figure 1. Serum $\tau$ protein levels following TBI, shown as line diagrams with standard deviations. Serum $\tau$ protein levels increased soon after TBI and reached a peak $\sim 2$ days after the injury. The mean serum $\tau$ protein levels were significantly higher in the severe TBI group compared with those in the mild and moderate TBI groups. ${ }^{*} \mathrm{P}<0.05$ and ${ }^{* *} \mathrm{P}<0.0001$, vs. mild and moderate TBI groups. TBI, traumatic brain injury.

centrifuged at $1,000 \mathrm{x}$ g for $15 \mathrm{~min}$ at $4^{\circ} \mathrm{C}$. Subsequently, the serum samples were frozen and stored at $-80^{\circ} \mathrm{C}$ until further analysis. The $\tau$ protein levels in the serum were measured using the Human $\tau$ Proteins Enzyme-Linked Immunosorbent Assay (ELISA) kit (CSB-E12011h; Cusabio Biotech Co., Ltd., Wuhan, China), according to a previous study (14). The minimum detectable concentration of $\tau$ protein was $15.6 \mathrm{pg} / \mathrm{ml}$, according to the manufacturer's protocol. Prior to analysis of the serum concentration of $\tau$ protein, a standard dilution curve was constructed using standard solutions provided with the ELISA kit. The dilution curve of the serum samples was partial to the standard dilution curve, in order to ensure the accuracy of the measurements.

Outcome assessment. Outcomes were assessed 1 year after TBI. The outcomes were quantified using the Extended Glasgow Outcome Scale (GOS-E) (15), and then classified into the good (GOS-E score, 5-8) and poor (GOS-E score, 1-4) outcome groups. The information was predominantly collected in the Outpatient Department at the Wuhan Central Hospital, although certain patients were interviewed by telephone or mail to identify their neurological outcome.

Statistical analysis. Data are expressed as the mean \pm standard deviation and were analyzed using the SPSS version 10.0 statistical software package (SPSS, Inc., Chicago, IL, USA). Mean values in two or more groups were analyzed using Student's t-test and protected t-test (one-way analysis of variance). Receiver operating characteristic (ROC) curves were used to determine the $\tau$ protein level that was able to yield the best sensitivity and specificity for predicting the patient outcome or mortality. The area under the ROC (AUC) was calculated using the SPSS software. Statistically significant differences were determined by $\mathrm{P}<0.05$.

\section{Results}

Serum $\tau$ protein levels. $\tau$ protein is undetectable in the serum of healthy patients (9). The serum $\tau$ protein levels increased immediately following TBI. At $\sim 2$ days post-injury, the protein levels peaked and then decreased gradually, although, in 
Table I. Patient data regarding patient numbers, mean serum $\tau$ protein levels and statistical P-values.

\begin{tabular}{lcccr}
\multirow{2}{*}{$\begin{array}{l}\text { Time point } \\
\text { after TBI }\end{array}$} & \multicolumn{3}{c}{ Mean serum $\tau$ protein levels in TBI groups, $(\mathrm{pg} / \mathrm{ml})$} & \\
\cline { 2 - 4 } & Mild $(\mathrm{n}=20)$ & Moderate $(\mathrm{n}=19)$ & Severe (patients) & P-value \\
\hline $12 \mathrm{~h}$ & $21.52 \pm 3.82$ & $23.79 \pm 7.15$ & $31.04 \pm 16.89(\mathrm{n}=17)$ & $<0.0500$ \\
1 day & $27.44 \pm 4.12$ & $49.97 \pm 9.77$ & $135.67 \pm 28.91(\mathrm{n}=17)$ & $<0.0001$ \\
2 days & $39.14 \pm 3.78$ & $85.58 \pm 12.72$ & $351.02 \pm 73.80(\mathrm{n}=17)$ & $<0.0001$ \\
3 days & $33.46 \pm 3.90$ & $73.56 \pm 11.57$ & $248.12 \pm 52.67(\mathrm{n}=16)$ & $<0.0001$ \\
4 days & $31.55 \pm 4.89$ & $65.66 \pm 10.45$ & $201.19 \pm 46.46(\mathrm{n}=16)$ & $<0.0001$ \\
7 days & $29.54 \pm 3.15$ & $39.22 \pm 9.28$ & $63.96 \pm 14.45(\mathrm{n}=14)$ & $<0.0001$ \\
14 days & $28.35 \pm 2.69$ & $37.44 \pm 8.45$ & $93.59 \pm 29.98(\mathrm{n}=14)$ & $<0.0001$ \\
\hline
\end{tabular}

Data presented as the mean \pm standard deviation. TBI, traumatic brain injury.

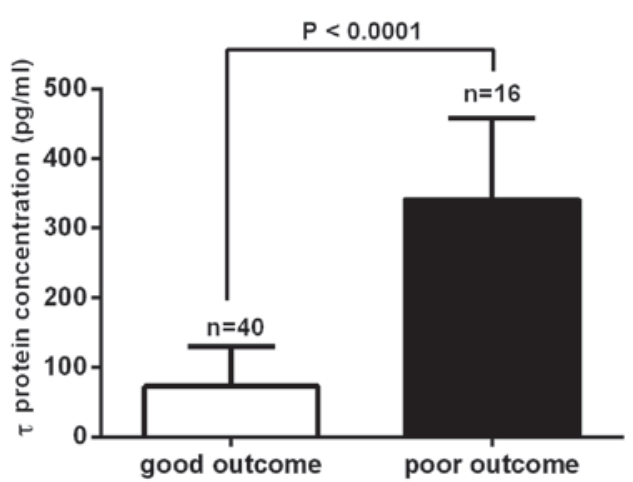

Figure 2. Serum $\tau$ protein levels in the good and poor outcome group. Mean serum $\tau$ protein levels were significantly higher in the poor outcome group, as compared with those in the good outcome group $(\mathrm{P}<0.0001)$.

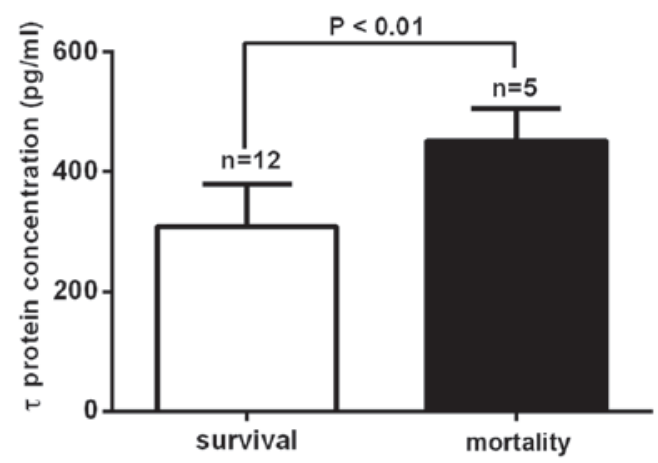

Figure 3. Serum $\tau$ protein levels in the mortality and survival cases in the severe traumatic brain injury group. The mean serum $\tau$ protein levels were significantly higher in the mortality cases than in the survival cases $(\mathrm{P}<0.01)$.

the severe TBI group, the serum $\tau$ protein levels increased slightly between days 7 and 14 (Fig. 1). The mean serum $\tau$ protein levels on day 2 were $39.14 \pm 3.78 \mathrm{pg} / \mathrm{ml}$ in the mild TBI group, $85.58 \pm 12.72 \mathrm{pg} / \mathrm{ml}$ in the moderate TBI group and $351.02 \pm 73.80 \mathrm{pg} / \mathrm{ml}$ in the severe TBI group. Statistically significant differences were found among the three groups $(\mathrm{P}<0.05$ at $12 \mathrm{~h}$ and $\mathrm{P}<0.0001$ at days $2-14$, after TBI). Data regarding the mean serum $\tau$ protein levels, patient numbers and P-values are summarized in Table I.

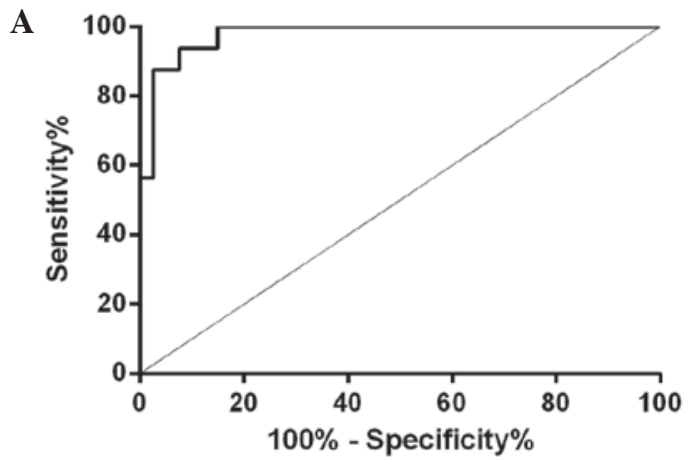

B

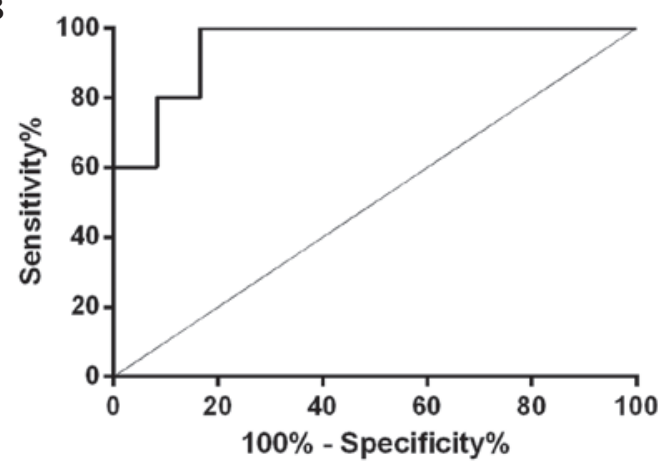

Figure 4. ROC curve showing the specificity and sensitivity of serum $\tau$ protein levels on day 2 after TBI for (A) 1-year poor outcome (GOS-E, 1-4), and (B) 1-year mortality (GOS-E, 1) in the severe TBI group. The AUC of the outcome curve was 0.9781 (95\% CI, 0.9472-1.009; $\mathrm{P}<0.0001$ ), whereas the AUC of the mortality rate curve was 0.9500 (95\% CI, 0.8510-1.049; P<0.01). ROC, receiver operating characteristic; TBI, traumatic brain injury; AUC, area under the curve; GOS-E, Extended Glasgow Outcome Scale; CI, confidence interval.

Outcome and survival. Outcomes were assessed 1 year after TBI using the GOS-E. In total, 40 patients were classified into the good outcome group and 16 patients, including 2 cases in the moderate TBI group and 14 cases in the severe TBI group, were classified into the poor outcome group. Subsequently, the mean serum $\tau$ protein levels on day 2 post-TBI between these groups were compared. The mean serum $\tau$ protein level was $341.43 \pm 29.29 \mathrm{pg} / \mathrm{ml}$ for the poor outcome group and $72.85 \pm 8.99 \mathrm{pg} / \mathrm{ml}$ for the good outcome group. This suggested that the $\tau$ protein level was significantly higher in the poor outcome group, as compared with the good outcome 
group ( $\mathrm{P}<0.0001$; Fig. 2). In total, 5 cases of mortality were observed in the patient cohort of the present study: 1 patient succumbed to the disease on day 3 after TBI, 2 patients on day 6 and 2 patients within 6 months after discharge from the hospital. Furthermore, all cases of mortality were patients from the severe TBI group. A significantly higher mean serum $\tau$ protein level was observed in the mortality cases $(452.04 \pm 24.23 \mathrm{pg} / \mathrm{ml})$, as compared with that of cases that survived $(309.06 \pm 20.55 \mathrm{pg} / \mathrm{ml})$ in the severe TBI group (P<0.01; Fig. 3).

Sensitivity and specificity. Using ROC curve analysis, a sensitivity of $93.75 \%$ and a specificity of $92.50 \%$ were detected for a poor 1-year outcome when the serum $\tau$ protein levels were $>116.04 \mathrm{pg} / \mathrm{ml}$ on day 2 after TBI. The calculated AUC was 0.9781 [95\% confidence interval (CI), 0.9472-1.009; $\mathrm{P}<0.0001$; Fig. 4A]. Patients from the severe TBI group that succumbed to the disease had a cut-off level of serum $\tau$ protein level on day 2 of $>372.1 \mathrm{pg} / \mathrm{ml}$, with a sensitivity of $100 \%$ and specificity of $83.33 \%$, with a calculated AUC of $0.9500(95 \%$ CI, 0.8510-1.049; P<0.01; Fig. 4B).

\section{Discussion}

Previous studies have employed TBI animal models in which damaged neurons enter a pathological cascade subsequent to injury, including cytoskeletal changes resulting in the loss of microtubule density $(16,17)$. This TBI-induced loss of microtubule density has been found to be associated with a $45 \%$ decrease in the levels of microtubule-associated proteins in previous immunochemical studies $(18,19)$. This suggests that microtubule-associated proteins may serve as potential biomarkers for TBI. Therefore, the present study investigated the potential of using $\tau$ protein as a biomarker of TBI.

$\tau$ protein is a small phosphor protein detected in the axonal compartments of neurons, which binds with microtubules, promoting their stability and assembly $(20,21)$. Human brain $\tau$ protein has six isoforms, with a molecular mass of 48-67 kDa, upon sodium dodecyl sulfate-polyacrylamide gel electrophoresis $(22,23)$. Increased levels of CSF $\tau$ protein are a possible sign of axonal injury and have been reported in Alzheimer's disease (24). While $\tau$ protein can be measured in the CSF of both healthy and pathological cases, its detection in the serum of healthy individuals is difficult (8). However, $\tau$ protein becomes detectable following TBI, since the damage to axons results in its release from CNS neurons (24). In the clinical field, serum $\tau$ protein has the advantage that it can be measured by less invasive methods compared with those used to measure CSF $\tau$ protein (25). Numerous studies revealed that $\tau$ protein levels are higher in CSF in severe TBI patients, but only a limited number of studies have investigated the serum $\tau$ protein levels (9,26-28). In addition, previous studies focused only on severe TBI patients rather than on the full spectrum of TBI patients, although it has been reported that serum $\tau$ protein levels increased even in mild TBI patients $(19,29)$. Therefore, the course of serum $\tau$ protein levels subsequent to TBI has not been extensively studied.

In the present study, the serum $\tau$ protein levels in the full spectrum of TBI patients (mild, moderate and severe cases) were detected at different time points subsequent to TBI. The results showed that the serum $\tau$ protein levels increased soon after TBI. Approximately 2 days after the injury, the protein levels reached a peak value, and then decreased gradually. Between days 7 and 14, there was a slight increase in serum $\tau$ protein in the severe group. This increase may be due to the increase of $\tau$ protein phosphorylation, which was likely caused by secondary cerebral ischemia damage post-trauma. However, this should be verified in future studies. In addition, the mean serum $\tau$ protein levels were found to be significantly higher in the severe TBI group, as compared with those in the mild and moderate groups (severe group levels $>$ moderate group levels $>$ mild group levels; $\mathrm{P}<0.05$ ), which indicated that the serum $\tau$ protein levels may perfectly reflect the severity of TBI.

Certain authors have shown that there is a positive correlation between high CSF $\tau$ protein levels and poor patient outcome $(8,30,31)$. In order to determine whether there was also a positive correlation between serum $\tau$ protein levels and patient outcome, the present study compared the serum $\tau$ protein levels in the poor and good 1-year outcome groups. The study focused on the serum $\tau$ protein levels on day 2 after TBI, since day 2 showed the most significant differences among the three groups and thus was the most representative. The results demonstrated that the mean serum $\tau$ protein levels on day 2 were significantly higher in the poor outcome group compared with those in the good outcome group. An ROC curve analysis evaluating the ability of serum $\tau$ protein levels to predict poor outcome showed an AUC value of 0.9781, with a $93.75 \%$ sensitivity and $92.50 \%$ specificity when the $\tau$ protein level was $>116.04 \mathrm{pg} / \mathrm{ml}$ on day 2 after TBI. Furthermore, the current study detected a sensitivity of $100 \%$ and a specificity of $83.33 \%$ for 1-year mortality when the serum $\tau$ protein level on day 2 was $>372.1 \mathrm{pg} / \mathrm{ml}$.

In conclusion, the study clearly showed the early dynamic course of serum $\tau$ protein levels following TBI. The mean serum $\tau$ protein levels were significantly higher in the severe TBI group compared with those in the mild and moderate group. In addition, a positive correlation was observed between high serum $\tau$ protein levels and poor outcome in TBI patients. Therefore, the findings of the current study suggest that serum $\tau$ protein may serve as a potential biomarker used to evaluate the severity and predict the outcome of TBI patients.

\section{Acknowledgements}

The present study was partially supported by grants from the National Natural Science Foundation of China (grant no. 81101620) and Clinical Project of Wuhan Health Bureau (grant no. WX14B08). Mr. Junwen Wang would like to thank Miss. Shunying Liu (Wuhan Central Hospital) for her great support in this study.

\section{References}

1. Chiu WT, Huang SJ, Tsai SH, Lin JW, Tsai MD, Lin TJ and Huang WC: The impact of time, legislation, and geography on the epidemiology of traumatic brain injury. J Clin Neurosci 14: 930-935, 2007.

2. Lin JW, Tsai SH, Tsai WC, Chiu WT, Chu SF, Lin CM, Yang CM and Hung CC: Survey of traumatic intracranial hemorrhage in Taiwan. Surgical Neurol 66 (Suppl 2): S20-S25, 2006. 
3. Marklund N, Blennow K, Zetterberg H, Ronne-Engström E, Enblad P and Hillered L: Monitoring of brain interstitial total tau and beta amyloid proteins by microdialysis in patients with traumatic brain injury. J Neurosurg 110: 1227-1237, 2009.

4. Teasdale G and Jennett B: Assessment of coma and impaired consciousness. A practical scale. Lancet 2: 81-84, 1974.

5. Pedersen AR, Severinsen K and Nielsen JF: The effect of age on rehabilitation outcome after traumatic brain injury assessed by the Functional Independence Measure (FIM). Neurorehabil Neural Repair 29: 299-307, 2015.

6. Buee L, Bussière T, Buée-Scherrer V, Delacourte A and Hof PR: Tau protein isoforms, phosphorylation and role in neurodegenerative disorders. Brain Res Brain Res Rev 33: 95-130, 2000

7. Goedert M, Spillantini MG, Cairns NJ and Crowther RA Tau proteins of Alzheimer paired helical filaments: Abnorma phosphorylation of all six brain isoforms. Neuron 8: 159-168, 1992.

8. Ost M, Nylén K, Csajbok L, Ohrfelt AO, Tullberg M, Wikkelsö C, Nellgård $\mathrm{P}$, Rosengren L, Blennow K and Nellgărd $\mathrm{B}$ : Initial CSF total tau correlates with 1-year outcome in patients with traumatic brain injury. Neurology 67: 1600-1604, 2006.

9. Takahashi K, Hasegawa S, Maeba S, Fukunaga S, Motoyama M, Hamano H and Ichiyama T: Serum tau protein level serves as a predictive factor for neurological prognosis in neonatal asphyxia. Brain Dev 36: 670-675, 2014.

10. Amadoro G, Corsetti V,Sancesario GM,Lubrano A, Melchiorri G Bernardini S, Calissano P and Sancesario G: Cerebrospinal fluid levels of a 20-22 kDa NH2 fragment of human tau provide a novel neuronal injury biomarker in Alzheimer's disease and other dementias. J Alzheimers Dis 42: 211-226, 2014.

11. Clarke NA, Hartmann T, Jones EL, Ballard CG and Francis PT: Antipsychotic medication is associated with selective alterations in ventricular cerebrospinal fluid Abeta 40 and tau in patient with intractable unipolar depression. Int J Geriatr Psychiatry 26: 1283-1291, 2011.

12. Hulstaert F, Blennow K, Ivanoiu A, Schoonderwaldt HC Riemenschneider M, De Deyn PP, Bancher C, Cras P, Wiltfang J, Mehta PD, et al: Improved discrimination of $\mathrm{AD}$ patients using beta-amyloid (1-42) and tau levels in CSF. Neurology 52 $1555-1562,1999$.

13. Brain Trauma Foundation; American Association of Neurological Surgeons, Joint Section on Neurotrauma and Critical Care: Management and Prognosis of Severe Traumatic Brain Injury. Brain Trauma Foundation, New York, NY, USA pp449, 2000.

14. Blennow K and Fredman P: Detection of cerebrospinal fluid leakage by isoelectric focusing on polyacrylamide gels with silver staining using the PhastSystem. Acta Neurochir (Wien) 136 : $135-139,1995$

15. Wilson JT, Pettigrew LE and Teasdale GM: Structured interviews for the Glasgow Outcome Scale and the extended Glasgow Outcome Scale: Guidelines for their use. J Neurotrauma 15 573-585, 1998.

16. Maxwell WL, Donnelly S, Sun X, Fenton T, Puri N and Graham DI: Axonal cytoskeletal responses to nondisruptive axonal injury and the short-term effects of posttraumatic hypothermia. J Neurotrauma 16: 1225-1234, 1999.

17. Pettus EH and Povlishock JT: Characterization of a distinct set of intra-axonal ultrastructural Changes associated with traumatically induced alteration in axolemmal permeability. Brain Res 722: 1-11, 1996.
18. Posmantur RM, Kampfl A, Liu SJ, Heck K, Taft WC, Clifton GL and Hayes RL: Cytoskeletal derangements of cortical neuronal processes three hours after traumatic brain injury in rats: An immunofluorescence study. J Neuropathol Exp Neurol 55: 68-80, 1996.

19. TaftWC,Yang K,DixonCEandHayesRL:Microtubule-associated protein 2 levels decrease in hippocampus following traumatic brain injury. J Neurotrauma 9: 281-290, 1992.

20. Vos PE, Lamers KJ, Hendriks JC, van Haaren M, Beems T, Zimmerman C, van Geel W, de Reus H, Biert J and Verbeek MM: Glial and neuronal proteins in serum predict outcome after severe traumatic brain injury. Neurology 62: 1303-1310, 2004.

21. Zanier ER, Zoerle T, Fiorini M, Longhi L, Cracco L, Bersano A, Branca V, Benedetti MD, De Simoni MG, Monaco S and Stocchetti N: Heart-fatty acid-binding and tau proteins relate to brain injury severity and long-term outcome in subarachnoid haemorrhage patients. Br J Anaesth 111: 424-432, 2013

22. Huber BR, Meabon JS, Martin TJ, Mourad PD, Bennett R, Kraemer BC, Cernak I, Petrie EC, Emery MJ, Swenson ER, et al: Blast exposure causes early and persistent aberrant phospho- and cleaved-tau expression in a murine model of mild blast-induced traumatic brain injury. J Alzheimers Dis 37: 309-323, 2013.

23. Neher MD, Keene CN, Rich MC, Moore HB and Stahel PF: Serum biomarkers for traumatic brain injury. South Med J 107: 248-255, 2014.

24. Vandermeeren M, Mercken M, Vanmechelen E, Six J, van de Voorde A, Martin JJ and Cras P: Detection of tau proteins in normal and Alzheimer's disease cerebrospinal fluid with a sensitive sandwich enzyme-linked immunosorbent assay. J Neurochem 61: 1828-1834, 1993.

25. Liliang PC, Liang CL, Lu K, Wang KW, Weng HC, Hsieh CH, Tsai YD and Chen HJ: Relationship between injury severity and serum tau protein levels in traumatic brain injured rats. Resuscitation 81: 1205-1208, 2010

26. Shiihara T, Miyake T, Izumi S, Sugihara S, Watanabe M, Takanashi J, Kubota M and Kato M: Serum and CSF biomarkers in acute pediatric neurological disorders. Brain Dev 36: 489-495, 2014.

27. Shahim P, Tegner Y, Wilson DH, Randall J, Skillbäck T, Pazooki D, Kallberg B, Blennow K and Zetterberg H: Blood biomarkers for brain injury in concussed professional ice hockey players. JAMA Neurol 71: 684-692, 2014.

28. Zemlan FP, Jauch EC, Mulchahey JJ, Gabbita SP, Rosenberg WS, Speciale SG and Zuccarello M: C-tau biomarker of neuronal damage in severe brain injured patients: Association with elevated intracranial pressure and clinical outcome. Brain Res 947: 131-139, 2002.

29. Guzel A, Karasalihoglu S, Aylanç H, Temizöz O and Hiçdönmez T: Validity of serum tau protein levels in pediatric patients with minor head trauma. Am J Emerg Med 28: 399-403, 2010.

30. Rubenstein R, Chang B, Davies P, Wagner AK, Robertson CS and Wang KK: A Novel, ultrasensitive assay for tau: Potential for assessing traumatic brain injury in tissues and biofluids. J Neurotrauma 32: 342-352, 2015.

31. Zhang ZY, Zhang LX, Dong XQ, Yu WH, Du Q, Yang DB, Shen YF, Wang H, Zhu Q, Che ZH, et al: Comparison of the performances of copeptin and multiple biomarkers in long-term prognosis of severe traumatic brain injury. Peptides 60: 13-17, 2014. 